\title{
Amygdala $\alpha$-Synuclein Pathology in the Population-Based Vantaa 85+ Study
}

\author{
Anna Raunio $^{\mathrm{a}}$, Liisa Myllykangas ${ }^{\mathrm{a}}$, Mia Kero $^{\mathrm{a}}$, Tuomo Polvikoski ${ }^{\mathrm{c}}$, Anders Paetau ${ }^{\mathrm{a}}$ \\ and Minna Oinas ${ }^{\mathrm{a}, \mathrm{b}, *}$ \\ ${ }^{a}$ Department of Pathology, University of Helsinki and Helsinki University Hospital, Helsinki, Finland \\ ${ }^{\mathrm{b}}$ Department of Neurosurgery, University of Helsinki and Helsinki University Hospital, Helsinki, Finland \\ ${ }^{\mathrm{c}}$ Institute of Neuroscience, Newcastle University, Newcastle Upon Tyne, UK
}

Handling Associate Editor: Irina Alafuzoff

Accepted 28 March 2017

\begin{abstract}
We investigated the frequency of Lewy-related pathology (LRP) in the amygdala among the population-based Vantaa $85+$ study. Data of amygdala samples $(\mathrm{N}=304)$ immunostained with two $\alpha$-synuclein antibodies (clone 42 and clone 5G4) was compared with the previously analyzed LRP and AD pathologies from other brain regions. The amygdala LRP was present in one third (33\%) of subjects. Only 5\% of pure AD subjects, but $85 \%$ of pure DLB subjects had LRP in the amygdala. The amygdala LRP was associated with dementia; however, the association was dependent on LRP on other brain regions, and thus was not an independent risk factor. The amygdala-predominant category was a rare (4\%) and heterogeneous group.
\end{abstract}

Keywords: 80 and over, aged, $\alpha$-synuclein, Alzheimer's disease, amygdala, amygdala-predominant, Lewy body disease, Lewy-related pathology, population-based study

\section{INTRODUCTION}

Lewy-related pathology (LRP) characterized by aggregated $\alpha$-synuclein in the form of Lewy bodies and Lewy neurites is a pathological hallmark of Parkinson's disease (PD) and dementia with Lewy bodies (DLB) [1]. In addition to PD and DLB, a substantial number of subjects with Alzheimer's disease (AD) develop LRP [2]. In some of the AD patients, LRP confines to the amygdala [3] instead of hierarchically spreading from the medulla to cerebral cortex as has been hypothesized to occur in the context of PD and DLB $[4,5]$.

\footnotetext{
${ }^{*}$ Correspondence to: Minna Oinas, Department of Pathology, University of Helsinki, P.O. Box 21 (Haartmaninkatu 3), FI-00014 University of Helsinki, Finland. Tel.: +358 50427 0394; E-mail: minna.oinas@helsinki.fi.
}

Neuropathological consensus recommendation for the diagnosis of DLB is analogical to the hypothesized progression of the pathology and thus proposes the disease to be categorized in the brainstem, limbic, and diffuse neocortical forms based on a semiquantitative scoring of the $\alpha$-synuclein pathology in various brain regions [6]. However, because of the presence of individuals with LRP confined to the amygdala, not all findings in referral- and community-based study cohorts fit to these categories and therefore inclusion of an additional amygdala-predominant category has been suggested [7]. In such cases the LRP load in the amygdala is expected to exceed the load seen in the brainstem [8].

The amygdala-predominant LRP has been proposed to be AD specific [9], but neither populationnor community-based studies have confirmed 
this [10-15]. On the other hand, the potential selection biases related with various study designs make interpretations problematic, thus increasing the need for true population-based cohorts in research $[16,17]$. Unfortunately, several of the population-based studies on LRP lack the LRP data on amygdala due to, for example, different sampling guidelines at the time when the study protocol for the follow-up study had been planned [13].

This study aimed to assess the prevalence of the amygdala LRP in elderly and to focus on the characteristics of the amygdala-predominant category in the population-based Vantaa 85+ study. The study complements our previous study on $\alpha$-synuclein pathology in this same cohort [2].

\section{MATERIALS AND METHODS}

The population-based Vantaa 85+ study includes all 601 citizens of the city of Vantaa aged 85 years or over on April 1, 1991. Of them, 565 eligible subjects died during the 10-year follow-up constituting our study cohort. The neuropathologic examination with clinical data was available in 304 (54\%). The study design and characteristics of the autopsied cohort versus whole study cohort has been described in detail earlier [2, 18].

The present study includes the amygdala samples from coronal sections of the left hemisphere fixed in phosphate-buffered $4 \%$ formaldehyde for at least seven years (amygdala was not included in the original sampling protocol created in 1991). Due to the long tissue fixation time, two different mouse monoclonal $\alpha$-synuclein antibodies were used for detection of the LRP: 1) Clone 42 (Transduction Laboratories, Lexington, KY, USA), diluted 1:800 and 2) Clone 5G4 (AJ Roboscreen $\mathrm{GmbH}$, Leipzig, Germany), diluted 1:1000. The amygdala slides were immunostained with Transduction clone 42 antibody as formerly described $[2,19]$. The clone 5G4 immunostaining was performed using LabVision LV-1 Autostainer and Dako ADVANCETM detection system. Preceding antigen retrieval was accomplished with Dako PT-module with citrate buffer ( $\mathrm{pH}$ 6.0) followed by $98 \%$ formic acid treatment.

The whole cross-sectional area of the amygdala in each section was assessed semiquantitatively (none $=0$, mild $=1$, moderate $=2$, severe $=3$, very severe $=4$ ) for LRP with magnification of $100 \times$. The score given represented the most severely affected area in the amygdala section. If scores given were distinct between different antibodies, the higher score was used for analyses. An amygdala-predominant category was formed as previously suggested [7], in addition to the brainstem, limbic and diffuse neocortical categories proposed by the DLB Consortium $[6,20]$. For the amygdala-predominant category, only mild LRP was allowed at the substantia nigra and cingulate region, and none at the frontal cortex [7]. The LRP in the amygdala also had to exceed the brainstem involvement as notified by the guidelines of the BrainNet Europe Consortium [8]. Additionally, transentorhinal cortex was included in the study and only mild LRP score was allowed. Neocortical regions (frontal, temporal, and parietal) were required to remain free of $\alpha$-synuclein pathology. LRP in the other brain areas has been evaluated previously according to the consensus guidelines for the diagnosis of DLB [2,6]. The assessment of the dementia status, Braak NFT stage and CERAD score has been described earlier [2, 18]. For the comparison analyses, four groups were created based on our earlier study [2]; negative group of 60 subjects without LRP and Braak stage 0 to II AD pathology; pure DLB group of 26 subjects with brainstem, limbic, or neocortical type of LRP with Braak stage 0 to II AD pathology; ADLB group of 71 subjects with brainstem, limbic, or neocortical type of LRP with Braak stage III to VI AD pathology; and pure AD group of 134 subjects with Braak stage III to VI AD pathology and no LRP.

For statistical analyses, SPSS 24.0.0.0 program for Mac (SPSS Inc., Chicago, IL) was applied. For categorical variables, the differences between the groups were analyzed with Chi-Squared test. Logistic regression analysis was used to assess association of several predictor variables with dichotomous dependent variables. All comparisons were adjusted for age at death and gender.

\section{RESULTS}

LRP was present in one third of the amygdala samples $(101 / 304,33 \%$, Table 1a). The amygdala LRP associated significantly with the most widespread AD pathology when adjusted for gender and age at death (high CERAD score OR 2.26, $p=0.011$; high Braak stage OR 2.94, $p=0.002$ ). A strong correlation existed between the amygdala LRP and that of the other brain regions (OR 131.17). In the pure DLB group, $85 \%$ (22/26) had LRP in the amygdala; in the 
Table 1a

The characteristics of the neuropathologically examined subpopulation of Vantaa 85+ Study stratified according to the $\alpha$-synuclein positivity in the amygdala regions. The general description of the cohort was formerly published [2]

\begin{tabular}{|c|c|c|c|c|c|}
\hline Characteristic $^{\mathrm{a}}$ & $\begin{array}{c}\text { Neuropathologic } \\
\text { subpopulation } \\
n=304 \\
\end{array}$ & $\begin{array}{c}\text { Amygdala } \\
\alpha \text {-syn pos } \\
n=101 \\
\end{array}$ & $\begin{array}{c}\text { Amygdala } \\
\alpha \text {-syn neg } \\
n=203\end{array}$ & OR $(95 \% \mathrm{CI})^{\mathrm{b}}$ & $p$-value ${ }^{\mathrm{c}}$ \\
\hline \multicolumn{6}{|l|}{$\overline{\text { Dementia }}$} \\
\hline No & $108(36 \%)$ & $\begin{array}{c}23(23 \%, 21 \% \\
\text { of non-demented })\end{array}$ & $85(42 \%)$ & 1 & \\
\hline Yes & $196(64 \%)$ & $\begin{array}{c}78(77 \%, 40 \% \\
\text { of demented })\end{array}$ & $118(58 \%)$ & $2.54(1.47-4.40)^{*}$ & $<0.001^{*}$ \\
\hline \multicolumn{6}{|l|}{ AD Pathology } \\
\hline \multicolumn{6}{|l|}{ Braak stage $\mathrm{d}^{\mathrm{d}}$} \\
\hline $0-\mathrm{II}$ & $90(29 \%)$ & $23(23 \%)$ & $67(33 \%)$ & 1 & \\
\hline III-IV & $142(47 \%)$ & $43(42 \%)$ & $99(49 \%)$ & $1.32(0.72-2.42)$ & 0.363 \\
\hline $\mathrm{V}-\mathrm{VI}$ & $72(24 \%)$ & $35(35 \%)$ & $37(18 \%)$ & $2.94(1.50-5.76)$ & 0.002 \\
\hline \multicolumn{6}{|l|}{ CERAD score } \\
\hline None & $71(23 \%)$ & $16(16 \%)$ & $55(27 \%)$ & 1 & \\
\hline Sparse & $33(11 \%)$ & $7(7 \%)$ & $26(13 \%)$ & $1.01(0.37-2.77)$ & 0.991 \\
\hline Moderate-Frequent & $200(66 \%)$ & $78(77 \%)$ & $122(60 \%)$ & $2.26(1.21-4.24)$ & 0.011 \\
\hline \multicolumn{6}{|l|}{ LRP other brain regions $\mathrm{e}^{\mathrm{e}}$} \\
\hline No & $194(64 \%)$ & $8(8 \%)$ & $186(92 \%)$ & 1 & \\
\hline Yes & & & & $131.17(53.82-319.68)^{* *}$ & $<0.001^{* *}$ \\
\hline Non-classifiable & $13(4 \%)$ & $5(5 \%)$ & $8(4 \%)$ & & \\
\hline Brainstem & $8(3 \%)$ & $4(4 \%)$ & $4(2 \%)$ & & \\
\hline Limbic & $42(14 \%)$ & $37(37 \%)$ & $5(2 \%)$ & & \\
\hline Neocortical & $47(15 \%)$ & $47(46 \%)$ & $0(0 \%)$ & & \\
\hline
\end{tabular}

${ }^{\mathrm{a}}$ Each individual feature analyzed separately in a logistic regression model adjusted for age at death and gender. ${ }^{\mathrm{b}} \mathrm{OR}$ and $95 \% \mathrm{CI}$ adjusted for age at death and gender. ${ }^{\mathrm{c}} p$-value considered significant when less than $0.05 .{ }^{\mathrm{d}}$ Braak stage 0 -II, III-IV, V-VI. ${ }^{\mathrm{e}}$ Lewy related pathology classified [2] as negative, non-classifiable, brainstem, limbic and neocortical type. * Association between dementia and amygdala $\alpha$-synuclein pathology remained significant when adjusted with Braak stage ${ }^{\mathrm{d}}$ [OR 2.08 (1.17-3.70) $p$-value 0.013]. However, this association was lost when adjusted with LRP ${ }^{\mathrm{e}}$ [OR $1.26(0.46-3.45) p$-value 0.656]. ${ }^{* *}$ Defined by comparing subjects with any type of LRP versus those without Lewy related pathology. $\alpha$-syn, $\alpha$-synuclein pathology; pos, positive; neg, negative; OR, odds ratio; CI, confidence interval; AD, Alzheimer's disease; LRP, Lewy related pathology; non-classifiable, LRP confined to the hippocampal-transentorhinal region.

Table $1 b$

The characteristics of the formerly published AD and LRP pathologies [2] according to the amygdala $\alpha$-synuclein positivity

\begin{tabular}{lccccr}
\hline Characteristic $^{\mathrm{a}}$ & $\begin{array}{c}\text { Subjects } \\
\text { N (demented } \%)\end{array}$ & $\begin{array}{c}\text { Amygdala } \\
\alpha \text {-syn pos }\end{array}$ & $\begin{array}{c}\text { Amygdala } \\
\alpha \text {-syn neg }\end{array}$ & OR $\left(95 \%\right.$ CI) $^{\mathrm{b}}$ & $p$-value \\
\hline AD+LRP & & & & & \\
No & & & & & \\
DLB & $60(48 \%)$ & $1(2 \%)$ & $59(98 \%)$ & $297.36(31.10-2843.74)$ & $<0.001$ \\
ADLB & $26(73 \%)$ & $22(85 \%)$ & $4(15 \%)$ & $862.65(95.58-7786.01)$ & $<0.001$ \\
AD & $71(83 \%)$ & $66(93 \%)$ & $5(7 \%)$ & $3.27(0.39-27.52)$ & 0.275 \\
\hline
\end{tabular}

${ }^{\mathrm{a}}$ Each individual feature analyzed separately in a logistic regression model adjusted for age at death and gender. ${ }^{\mathrm{b}} \mathrm{OR}$ and $95 \% \mathrm{CI}$ adjusted for age at death and gender. ${ }^{\mathrm{c}} p$-value considered significant when less than 0.05. ${ }^{\mathrm{d}} \mathrm{AD}$ and Lewy related pathology: No, Braak stage 0-II; DLB, pure DLB - Braak stage 0-II and brainstem, limbic, or neocortical LRP; ADLB, Braak stage III-VI and brainstem, limbic, or neocortical LRP; AD, pure AD - Braak stage III-VI. 13 previously unclassifiable cases with LRP confined to hippocampal-transentorhinal region were not included for this analysis.

ADLB group, 93\% (66/71) had amygdala LRP; and in the pure AD group, only 5\% (7/134) had amygdala LRP (Table 1b). Subjects with pure DLB were almost 300 times more likely to harbor amygdala LRP compared to those without LRP on other brain regions and Braak stage 0 to II (OR 297.36, $p<0.001)$.

Of the amygdala LRP subjects, $78(77 \%)$ were demented (Table 1a). 40\% (78/196) of the demented subjects and $21 \%(23 / 108)$ of the non-demented subjects had LRP in the amygdala. The amygdala LRP was associated with dementia (OR 2.54, $p<0.001)$. This association remained significant when logistic regression analysis was adjusted with Braak stage (OR 2.08, $p=0.013$ ), but was lost when adjusted with classifiable (brainstem, limbic, or neocortical) LRP $(p=0.656)$. The amygdala LRP data only scarcely changed the LRP categories defined in our previous study (Table 2). 
Twelve cases $(12 / 304,3.9 \%)$ were categorized as amygdala-predominant, according to the criteria described above. $4.6 \%$ (9/196) of the demented subjects and $2.8 \%(3 / 108)$ of the non-demented subjects had amygdala-predominant LRP. The median age of death in the amygdala-predominant cases was 93.4 (range: 89.7-98.7) years. Nine (75\%) of the amygdala-predominant cases had been diagnosed with dementia and the median duration of dementia was 4.9 (range: 1.1-9.6) years. All but three cases had at least moderate CERAD score for neuritic plaques. The corresponding Braak stage varied from II to VI. One third were found to have high (V-VI) Braak stage. Seven amygdala-predominant cases had severe LRP in the amygdala, and $43 \%$ of them (3/7) showed high (V-VI) Braak stage. Only one subject had been reported to have visual hallucinations.

\section{DISCUSSION}

Although LRP has been increasingly studied in several settings, only very few population/community-based studies exist on the prevalence of amygdala-predominant LRP and its association with AD [10-13]. Our population-based cohort study of the very elderly show that one third of the population aged 85 years and over has LRP in the amygdala. However, the amygdala-predominant type remains sparse (12/304) in this age group. Although the overall amygdala LRP was associated with widespread AD pathology, it was not associated with pure AD. Instead, amygdala LRP was strongly associated with pure DLB. Furthermore, no clear correlation between the amygdala-predominant LRP and $\mathrm{AD}$ pathology was found, and only a third of subjects in the amygdala-predominant category had severe AD-type changes (Braak stage V-VI and CERAD score moderate or frequent).

The previous population/community-based studies on amygdala LRP have been largely variable in methods and study designs, and thus direct comparisons between the studies are problematic. The VITA study based on a community-based sample and using Clone 5G4 $\alpha$-synuclein antibody, appears to be most comparable to our study [12]. Prevalence of the amygdala-predominant LRP in that study was $4.6 \%$, resembling the corresponding prevalence figure in our study (3.9\%). However, they did not publish the overall prevalence of amygdala LRP [12]. Another population-based study, the CFAS study, based on different antibody and sampling strategy, found the prevalence of overall amygdala LRP to be lower compared to our study (22\% versus 33\%) [10]. In contrast, frequency of the amygdala-predominant cases in that study was higher $(10.6 \%)$ than in our series $(3.9 \%)$ [10]. In a community-based ADPR study, prevalence of the amygdala-predominant LRP was also $10.6 \%$ [7]. In all of these studies, the study subjects were somewhat younger (the age of death 85-86 years in the CFAS, 77-87 years in the VITA study, $84 \pm 6$ years in the ADPR study) than in our study (mean age at death $92.4 \pm 3.7$ years) $[2,7,10,12]$.

In our study, $40 \%$ of the demented subjects and $21 \%$ of non-demented subjects had LRP in the amygdala. The amygdala-predominant LRP was seen in $4.6 \%$ of demented and in $2.8 \%$ of non-demented subjects. In previous studies on clinical AD subjects $60.7 \%$ (88/145) prevalence of amygdala LRP has been reported [3]. Incidental LRP in the amygdala has been reported in variable frequencies $(4-17 \%)$

Table 2

The characteristics of the twelve amygdala-predominant subjects

\begin{tabular}{lccccccccc}
\hline Gender & SN & AC & Cing & Front & $\begin{array}{c}\text { Type of LRP } \\
\text { 2009 [2] }\end{array}$ & $\begin{array}{c}\text { Braak [27]/ } \\
\text { CERAD [28] }\end{array}$ & $\begin{array}{c}\text { Dementia } \\
\text { (Duration,y) }\end{array}$ & $\begin{array}{c}\text { VH } \\
\text { Age at } \\
\text { death }\end{array}$ \\
\hline F & 0 & 3 & 0 & 0 & Non-class & III/N & Yes (1.13) & No & 90.20 \\
F & 1 & 4 & 0 & 0 & Non-class & VI/F & Yes (4.61) & No & 90.47 \\
F & 1 & 4 & 1 & 0 & Limbic & IV/M & Yes (3.30) & No & 94.59 \\
F & 1 & 3 & 0 & 0 & Non-class & V/F & Yes (8.50) & Yes & 89.66 \\
F & 0 & 3 & 0 & 0 & Non-class & VI/M & Yes (9.68) & No & 95.54 \\
F & 0 & 1 & 0 & 0 & None & II/M & Yes (N/A) & No & 90.26 \\
F & 1 & 3 & 1 & 0 & Brainstem & III/M & Yes (4.99) & No & 96.84 \\
F & 1 & 2 & 0 & 0 & None & V/M & Yes (4.83) & No & 91.43 \\
M & 0 & 1 & 0 & 0 & None & IV/S & No & No & 96.40 \\
F & 0 & 1 & 0 & 0 & None & IV/M & No & No & 92.25 \\
M & 0 & 3 & 0 & 0 & Non-class & IV/M & Yes (5.31) & No & 98.73 \\
M & 1 & 2 & 0 & 0 & None & IV/N & No & No & 94.67 \\
\hline
\end{tabular}

The staging of $\alpha$-synuclein was graded semiquantitatively $(0=$ none, $1=$ mild, $2=$ moderate, $3=$ severe and $4=$ very severe $)$. SN, substantia nigra; AC, amygdala; Cing, cingulate cortex; Front, frontal cortex; LRP, Lewy related pathology; Non-class, LRP confined to the hippocampaltransentorhinal region; CERAD score: N, none; S, sparse; M, moderate; F, frequent; N/A, not available; VH, visual hallucinations. 
among the cognitively unimpaired subjects [16, 21]. The amygdala-predominant LRP frequencies $(2.2 \%$ and $3 \%$ ) resembled our findings $(2.8 \%$ of the nondemented subjects) [16, 21]. In a referral-based LADRS autopsy study on slightly younger demented subjects, $18 \%$ (23/125) had amygdala-predominant LRP (the mean age of death 78 years versus 93 years in our study) [7]. Furthermore, one study of 45 clinical DLB and 54 clinical PDD subjects reported no amygdala-predominant LRP cases in the DLB group and the frequency of $3.7 \%(2 / 54)$ in the PDD group [22].

Even though most synucleinopathies seem to follow hierarchical progress starting from medulla $[4,5]$, differently proceeding amygdala-predominant form has been proposed to be associated with AD especially with concomitant dementia in disease-based studies [3, 7, 9]. However, population-based studies reveal controversial results [10]. This is in line with our population-based study of very elderly, as we found only $1 / 3$ of the amygdala-predominant subjects to show severe AD type pathology (Braak V-VI and CERAD moderate or frequent).

We found an association between dementia and overall LRP in the amygdala. This association remained significant when adjusted for Braak stage, but lost its significance when adjusted for LRP on other brain areas, suggesting that amygdala LRP is not an independent risk factor for dementia. This is in contrast to the report of the VITA study, where the association between amygdala LRP and dementia lost its significance with adjustment for Braak stage [12]. The proportion of demented subjects in the amygdala-predominant category has varied from $39 \%-80 \%$ in different studies $[10,12]$. In our study, 9/12 (75\%) of the subjects in the amygdalapredominant category were clinically demented. Visual hallucinations have reported to be correlated with LRP in several studies [3, 23-25]. In our previous study, we found no association between visual hallucinations and brainstem, limbic, or neocortical LRP [2], and in the present study there was no association between the amygdala-predominant category and visual hallucinations either (Table 2).

The LRP of the amygdala has been reported to be unevenly distributed among vulnerable nuclei, mainly in the lateral, medial, and central nuclei [26]. Based on our experience on this study, we support the view that the most practical method for scoring is to locate the most severely damaged nuclei and count LRP within it [10], instead of scoring the average distribution of LRP in the whole amygdala.
We observed minor differences between consecutive slides stained with two separate antibodies (clone 42 and clone 5G4), but these differences proved to occur regardless of the antibody selection (data not shown). Our experience suggests that there are no major differences in the specificity and sensitivity of these two antibodies.

Our results suggest that among the very aged the amygdala LRP is present most often concomitantly with LRP on other brain regions. The amygdala LRP association with dementia seems to be dependent on LRP on other brain areas. Furthermore, the amygdala-predominant category appears a rare and heterogenic group with wide variation of AD-type pathology.

\section{ACKNOWLEDGMENTS}

We thank Tuija Järvinen and Leena Saikko for technical assistance, Dr. Terhi Peuralinna and IrmaLeena Notkola for their assistance with statistics, Dr. Auli Verkkoniemi for clinical evaluations during the baseline study of Vantaa 85+, and Counsellor in Medicine Leena Niinistö and Prof. emeritus Raimo Sulkava for establishing the Vantaa 85+ Study. This study was supported by Helsinki University Central Hospital competitive research fund, the Academy of Finland (294817) and the Finska Läkaresälskapet.

Authors' disclosures available online (http://j-alz. com/manuscript-disclosures/17-0104r1).

\section{REFERENCES}

[1] Spillantini MG, Schmidt ML, Lee VM, Trojanowski JQ, Jakes R, Goedert M (1997) Alpha-synuclein in Lewy bodies. Nature 388, 839-840.

[2] Oinas M, Polvikoski T, Sulkava R, Myllykangas L, Juva K, Notkola IL, Rastas S, Niinisto L, Kalimo H, Paetau A (2009) Neuropathologic findings of dementia with lewy bodies (DLB) in a population-based Vantaa $85+$ study. $J$ Alzheimers Dis 18, 677-689.

[3] Hamilton RL (2000) Lewy bodies in Alzheimer's disease: A neuropathological review of 145 cases using alpha-synuclein immunohistochemistry. Brain Pathol 10, 378-384.

[4] Braak H, Del Tredici K, Rub U, de Vos RA, Jansen Steur EN, Braak E (2003) Staging of brain pathology related to sporadic Parkinson's disease. Neurobiol Aging 24, 197-211.

[5] Dickson DW, Uchikado H, Fujishiro H, Tsuboi Y (2010) Evidence in favor of Braak staging of Parkinson's disease. Mov Disord 25(Suppl 1), S78-S82.

[6] McKeith IG, Dickson DW, Lowe J, Emre M, O'Brien JT, Feldman H, Cummings J, Duda JE, Lippa C, Perry EK, Aarsland D, Arai H, Ballard CG, Boeve B, Burn DJ, Costa D, Del Ser T, Dubois B, Galasko D, Gauthier S, Goetz CG, Gomez-Tortosa E, Halliday G, Hansen LA, Hardy J, 
Iwatsubo T, Kalaria RN, Kaufer D, Kenny RA, Korczyn A, Kosaka K, Lee VM, Lees A, Litvan I, Londos E, Lopez OL, Minoshima S, Mizuno Y, Molina JA, Mukaetova-Ladinska EB, Pasquier F, Perry RH, Schulz JB, Trojanowski JQ, Yamada M (2005) Diagnosis and management of dementia with Lewy bodies: Third report of the DLB Consortium. Neurology 65, 1863-1872.

[7] Leverenz JB, Hamilton R, Tsuang DW, Schantz A, Vavrek D, Larson EB, Kukull WA, Lopez O, Galasko D, Masliah E, Kaye J, Woltjer R, Clark C, Trojanowski JQ, Montine TJ (2008) Empiric refinement of the pathologic assessment of Lewy-related pathology in the dementia patient. Brain Pathol 18, 220-224.

[8] Alafuzoff I, Ince PG, Arzberger T, Al-Sarraj S, Bell J, Bodi I, Bogdanovic N, Bugiani O, Ferrer I, Gelpi E, Gentleman S, Giaccone G, Ironside JW, Kavantzas N, King A, Korkolopoulou P, Kovacs GG, Meyronet D, Monoranu C, Parchi P, Parkkinen L, Patsouris E, Roggendorf W, Rozemuller A, Stadelmann-Nessler C, Streichenberger N, Thal DR, Kretzschmar H (2009) Staging/typing of Lewy body related alpha-synuclein pathology: A study of the BrainNet Europe Consortium. Acta Neuropathol 117, 635652.

[9] Uchikado H, Lin WL, DeLucia MW, Dickson DW (2006) Alzheimer disease with amygdala Lewy bodies: A distinct form of alpha-synucleinopathy. J Neuropathol Exp Neurol 65, 685-697.

[10] Zaccai J, Brayne C, McKeith I, Matthews F, Ince PG (2008) Patterns and stages of alpha-synucleinopathy: Relevance in a population-based cohort. Neurology 70, 1042-1048.

[11] Zaccai J, Brayne C, Matthews FE, Ince PG (2015) Alphasynucleinopathy and neuropsychological symptoms in a population-based cohort of the elderly. Alzheimers Res Ther 7, 19.

[12] Kovacs GG, Milenkovic I, Wohrer A, Hoftberger R, Gelpi E, Haberler C, Honigschnabl S, Reiner-Concin A, Heinzl H, Jungwirth S, Krampla W, Fischer P, Budka H (2013) Non-Alzheimer neurodegenerative pathologies and their combinations are more frequent than commonly believed in the elderly brain: A community-based autopsy series. Acta Neuropathol 126, 365-384.

[13] Rahimi J, Kovacs GG (2014) Prevalence of mixed pathologies in the aging brain. Alzheimers Res Ther 6, 82.

[14] Robinson JL, Geser F, Corrada MM, Berlau DJ, Arnold SE, Lee VM, Kawas CH, Trojanowski JQ (2011) Neocortical and hippocampal amyloid-beta and tau measures associate with dementia in the oldest-old. Brain 134, 3708-3715.

[15] Kawas CH, Kim RC, Sonnen JA, Bullain SS, Trieu T, Corrada MM (2015) Multiple pathologies are common and related to dementia in the oldest-old: The $90+$ Study. Neurology 85, 535-542.

[16] Markesbery WR, Jicha GA, Liu H, Schmitt FA (2009) Lewy body pathology in normal elderly subjects. J Neuropathol Exp Neurol 68, 816-822.
[17] Zaccai J, Ince P, Brayne C (2006) Population-based neuropathological studies of dementia: Design, methods and areas of investigation-a systematic review. BMC Neurol 6, 2.

[18] Polvikoski T, Sulkava R, Myllykangas L, Notkola IL, Niinisto L, Verkkoniemi A, Kainulainen K, Kontula K, Perez-Tur J, Hardy J, Haltia M (2001) Prevalence of Alzheimer's disease in very elderly people: A prospective neuropathological study. Neurology 56, 1690-1696.

[19] Oinas M, Sulkava R, Polvikoski T, Kalimo H, Paetau A (2007) Reappraisal of a consecutive autopsy series of patients with primary degenerative dementia: Lewy-related pathology. APMIS 115, 820-827.

[20] McKeith IG, Galasko D, Kosaka K, Perry EK, Dickson DW, Hansen LA, Salmon DP, Lowe J, Mirra SS, Byrne EJ, Lennox G, Quinn NP, Edwardson JA, Ince PG, Bergeron C, Burns A, Miller BL, Lovestone S, Collerton D, Jansen EN, Ballard C, de Vos RA, Wilcock GK, Jellinger KA, Perry RH (1996) Consensus guidelines for the clinical and pathologic diagnosis of dementia with Lewy bodies (DLB): Report of the consortium on DLB international workshop. Neurology 47, 1113-1124.

[21] Elobeid A, Libard S, Leino M, Popova SN, Alafuzoff I (2016) Altered proteins in the aging brain. J Neuropathol Exp Neurol 75, 316-325.

[22] Hepp DH, Vergoossen DL, Huisman E, Lemstra AW, Netherlands Brain Bank, Berendse HW, Rozemuller AJ, Foncke EM, van de Berg WD (2016) Distribution and load of amyloid-( pathology in Parkinson disease and dementia with Lewy bodies. J Neuropathol Exp Neurol 75, 936-945.

[23] Tsuang D, Larson EB, Bolen E, Thompson ML, Peskind E, Bowen J, McCormick W, Teri L, Kukull W, Vavrek D, Montine T, Leverenz JB (2009) Visual hallucinations in dementia: A prospective community-based study with autopsy. Am J Geriatr Psychiatry 17, 317-323.

[24] Fujishiro H, Ferman TJ, Boeve BF, Smith GE, GraffRadford NR, Uitti RJ, Wszolek ZK, Knopman DS, Petersen RC, Parisi JE, Dickson DW (2008) Validation of the neuropathologic criteria of the third consortium for dementia with Lewy bodies for prospectively diagnosed cases. $\mathrm{J} \mathrm{Neu}$ ropathol Exp Neurol 67, 649-656.

[25] Harding AJ, Broe GA, Halliday GM (2002) Visual hallucinations in Lewy body disease relate to Lewy bodies in the temporal lobe. Brain 125, 391-403.

[26] Braak H, Braak E, Yilmazer D, de Vos RA, Jansen EN, Bohl J, Jellinger K (1994) Amygdala pathology in Parkinson's disease. Acta Neuropathol 88, 493-500.

[27] Braak H, Braak E (1991) Neuropathological stageing of Alzheimer-related changes. Acta Neuropathol 82, 239-259.

[28] Mirra SS, Heyman A, McKeel D, Sumi SM, Crain BJ, Brownlee LM, Vogel FS, Hughes JP, van Belle G, Berg L (1991) The Consortium to Establish a Registry for Alzheimer's Disease (CERAD). Part II. Standardization of the neuropathologic assessment of Alzheimer's disease. Neurology 41, 479-486. 